ENSAIO 


\title{
COSAS SIMPLES
}

http://dx.doi.org/10.1590/1984-0292/1328

Juan Carlos Gorlier ${ }^{\star}$

Universidad Nacional de Buenos Aires, Buenos Aires, Argentina Universidad Nacional de Mar del Plata, Mar del Plata, Buenos Aires, Argentina Universidad Nacional de Quilmes, Bernal, Buenos Aires, Argentina Fundación Centro Psicoanalítico Argentino, Buenos Aires, Argentina.

\section{RESUMEN}

El presente ensayo presenta algunas impresiones producidas por un cuadro de Paul Cézanne. Las auténticas conexiones se establecen por contagio, no por transmisión erudita. Cuando a fines del siglo 19 comienzan a emerger las obras de Cézanne, nadie, ni él mismo, entendía con claridad qué es lo que estaba en juego en ellas. Los primeros en vislumbrar la irrupción de una mutación profunda fueron algunos artistas, pintores, poetas, escritores, luego se sumaron algunos críticos y por fin varios filósofos.

Palabras-clave: Paul Cézanne; contagio; arte; pintura.

\section{Simple ThingS}

\begin{abstract}
The essay presents some impressions produced by a Paul Cézanne's picture. Authentic connections are contagious; they do not work through erudition. When by the end to the Nineteenth Century Cézanne's works start to emerge, nobody, not even himself, knew what it was all about. The first ones to have a glimpse of a mutation were some artists, painters, poets, writers, then slowly some critics joined them, and at last a few philosophers.
\end{abstract}

Keywords: Paul Cézanne; contagion; art; painting.

^ Dirección de envio: Universidad Nacional de Mar del Plata - Diagonal J. B. Alberdi 2695-

(7600) - Mar del Plata - Argentina.E-mail: juancgorlier@yahoo.com 


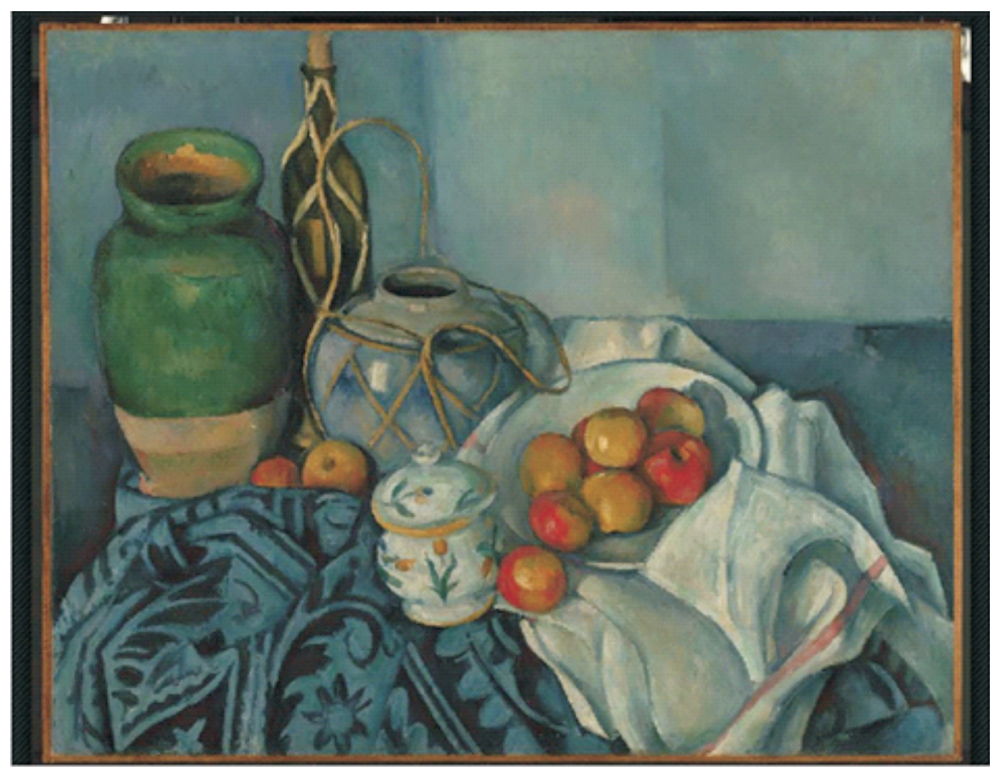

Paul Cézanne

Nature morte - óleo sobre lienzo, 1890-1894, 65.4 x 81.6 The J. Paul Getty Museum. Los Angeles Photo (C) The Paul Getty Museum. Disponible en: <http://www.getty.edu/art/gettyguide/ artObjectDetails? artobj=109325>. Digital image courtesy of the Getty's Open Content Program.

¿cuánto tiempo hay que detenerse ante un cuadro para entrar en él, para que él entre en uno?

no conviene tratar de ver antes de mirar, de oír antes de escuchar, de agarrar antes de palpar

¿cuánto tiempo es necesario para dejar de ver, para empezar a mirar?

la pintura es el arte de mirar sin apresurarse a ver algo

una botella, un jarrón, una jarra, una azucarera, un plato, algunas manzanas, un cubrecama y un mantel

cosas simples, ascéticas

no dicen donde están ni a quién le pertenecen

están en su propio lugar

en un espacio y un tiempo que sólo les pertenece a ellas

el cuadro invita a ir de lo conocido a lo desconocido

la mente debe aprender a acompañar la vista en lugar de dirigirla

debe olvidar todo lo aprendido

cuando uno entra al cuadro, trata de orientarse 
la pintura lo invita gentilmente a perderse

donde espera ver el ángulo que forman dos paredes al unirse, la pintura lo lleva a ver un panel de color celeste desvaído

lo lleva a perder la perspectiva

la pintura resiste y la vista se convierte en su aliada

hechizada por lo que ve, la vista deja de ser arrastrada por la mente y comienza a arrastrarla

las cosas están puestas de una manera convencional, como en una fotografía familiar

los más altos atrás, los más bajos adelante, todos apretujados en un espacio reducido

la botella está erguida

el jarrón verde está desencajado

la azucarera hace equilibrio

algunas manzanas desafían la ley de la gravedad

el cubrecama azul y el mantel blanco acentúan la sensación de caída

cada cosa tiene una forma, un color, una fisonomía que la singulariza

hay un equilibrio precario

la vista y la mente tienen que abandonar los apoyos

aprender a equilibrarse

para recuperar la perspectiva se puede intentar buscar de dónde viene la luz hay un pequeño rectángulo sobre el cuerpo de la jarra que salta a la vista un reflejo desvaído sobre el verde del jarrón unos brillos sobre los amarillos y los rojos de varias manzanas unas sombras que proyectan dos manzanas sobre el plato blanco se puede pensar que hay una ventana ubicada a la izquierda que la luz natural entra por ella que el pequeño rectángulo refleja la ventana se puede tratar de recuperar la perspectiva el cuadro insiste, gentil y delicadamente, en conducir la mirada más allá en llevarla ver algo que está y que no está, que es casi invisible una extraña luminosidad que brota de los colores y baña todo las verdaderas obras de arte no muestran cosas nuevas 
enseñan a comprender que lo que permite ver no se hace ver

este no es un cuadro bello, cuando uno entra en él no se siente como en su casa

las cosas parecen estar a la intemperie

la falta de personas, de muebles, ventanas, puertas o paredes, impide proyectar sobre ellas la medida humana

para volver a hacer pie se puede tratar de ver el espacio interior como si fuera un espacio exterior

es como descubrir una bisagra

la línea que separaba el suelo de la pared, se convierte en la línea del horizonte

la pared es el cielo, el suelo es el océano, el mantel una montaña

es la manera típica de ir de lo conocido a lo conocido

para que todo quede como estaba

para olvidar la experiencia fugaz de ver lo que no se da a ver, de pensar lo que resiste al pensar

para olvidar que por un momento se ha rozado lo desconocido

las auténticas obra de arte son espacios de experimentación

no están para ser contempladas

el cuerpo y la mente tienen que encontrar la manera de estar al mismo tiempo distendidos y tensos, distraídos y alertas, suspendidos y atentos

la atención tiende a visible, a lo manifiesto

la suspensión a lo invisible, a lo no manifiesto

se trata de buscar el punto de equilibrio entre la atención y la suspensión

se trata anticipar pero no tanto, de retener pero no todo

se trata de buscar la actitud justa

la búsqueda es interminable 


\section{REFERENCIAS}

CÉZANNE, P. Nature morte. óleo sobre lienzo, 1890-1894, 65.4 x 81.6. The J. Paul Getty Museum. Los Angeles Photo (C) The Paul Getty Museum. Disponible en: $\quad<$ http://www.getty.edu/art/gettyguide/artObjectDetails?artobj=109325>. Digital image courtesy of the Getty's Open Content Program.

DELEUZE, G. Analogie (1981). En: Francis Bacon: logique de la sensation. Paris: Seuil, 2002.

DENIS, M. Cézanne. En Théories, 1890-1910; du symbolisme et de Gauguin vers un nouvel ordre classique. Paris: L. Rouart \& J. Watelin, 1920.

FRY, R. Cézanne: a study of his development (1927). New York: Kessinger, 2004.

GASQUET, J. Cézanne (1921). Paris: Ancre Marine, 2003.

LAWRENCE, D. H. Introduction to these paintings (1929). En: Phoenix: the posthumous papers, 1936. London: Penguin, 1978.

MERLEAU-PONTY, M. Le doute de Cézanne (1945). En: Sens et Non-Sens Paris: Nagel, 1966.

Recibido: 02 de julio 2014 Aceptado: 03 de septiembre 2014 